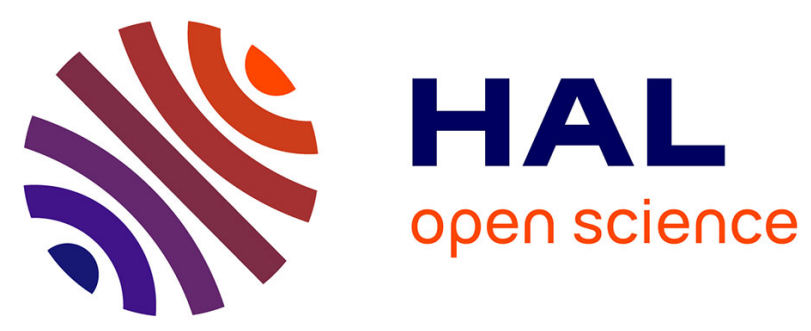

\title{
Mixed Valence Tungsten (IV,V) Compounds with Layered Structures (Part III*): Synthesis and Crystal Structure of Ag1-x[W2O2Cl6] and Investigations on the Ag+ Ion Mobility
}

Johannes Beck, Wilfried Hoffbauer, Christian Kusterer, Marcel Schieweling

\section{To cite this version:}

Johannes Beck, Wilfried Hoffbauer, Christian Kusterer, Marcel Schieweling. Mixed Valence Tungsten $(\mathrm{IV}, \mathrm{V})$ Compounds with Layered Structures (Part III*): Synthesis and Crystal Structure of Ag1-x[W2O2Cl6] and Investigations on the Ag+ Ion Mobility. Journal of Inorganic and General Chemistry / Zeitschrift für anorganische und allgemeine Chemie, 2010, 636 (9-10), pp.1827. 10.1002/zaac.201000080 . hal-00552461

\author{
HAL Id: hal-00552461 \\ https://hal.science/hal-00552461
}

Submitted on 6 Jan 2011

HAL is a multi-disciplinary open access archive for the deposit and dissemination of scientific research documents, whether they are published or not. The documents may come from teaching and research institutions in France or abroad, or from public or private research centers.
L'archive ouverte pluridisciplinaire HAL, est destinée au dépôt et à la diffusion de documents scientifiques de niveau recherche, publiés ou non, émanant des établissements d'enseignement et de recherche français ou étrangers, des laboratoires publics ou privés. 


\section{Mixed Valence Tungsten (IV,V) Compounds with Layered Structures (Part III*): Synthesis and Crystal Structure of Ag1-x[W202Cl6] and Investigations on the Ag+ Ion Mobility}

\begin{tabular}{|c|c|}
\hline Journal: & Zeitschrift für Anorganische und Allgemeine Chemie \\
\hline Manuscript ID: & zaac. 201000080 \\
\hline Wiley - Manuscript type: & Article \\
\hline $\begin{array}{r}\text { Date Submitted by the } \\
\text { Author: }\end{array}$ & 07-Feb-2010 \\
\hline Complete List of Authors: & $\begin{array}{l}\text { Beck, Johannes; University of Bonn, Inorganic Chemistry } \\
\text { Hoffbauer, Wilfried } \\
\text { Kusterer, Christian } \\
\text { Schieweling, Marcel }\end{array}$ \\
\hline Keywords: & $\begin{array}{l}\text { Halooxotungstates, Mixed valence compounds, Ion mobility, 109Ag } \\
\text { solid state NMR, Small Gap Semiconductivity }\end{array}$ \\
\hline
\end{tabular}

\section{\scholarONE" \\ Manuscript Central}




\title{
Mixed Valence Tungsten (IV,V) Compounds with Layered Structures (Part III*): Synthesis and Crystal Structure of $\mathrm{Ag}_{1-x}\left[\mathrm{~W}_{2} \mathrm{O}_{2} \mathrm{Cl}_{6}\right]$ and Investigations on the $\mathrm{Ag}^{+}$Ion Mobility
}

\author{
Johannes Beck**, Wilfried Hoffbauer, Christian Kusterer and Marcel Schieweling \\ Bonn, Institut für Anorganische Chemie der Universität
}

Received................................

Dedicated to Prof. Bernd Harbrecht on the Occasion of his $60^{\text {th }}$ Birthday

* Second Report: see ref. [2]

**Prof. Dr. J. Beck

Inst. f. Anorg. Chemie d. Universität

Gerhard-Domagk-Str. 1

D-53121 Bonn

e-mail: j.beck@uni-bonn.de 


\begin{abstract}
The reactions of metallic silver with tungsten tetrachlorideoxide $\mathrm{WOCl}_{4}$ or the reaction of $\mathrm{AgCl}$ with $\mathrm{WOCl}_{3}$, both at $690 \mathrm{~K}$, lead to $\mathrm{Ag}_{1-\mathrm{x}}\left[\mathrm{W}_{2} \mathrm{O}_{2} \mathrm{Cl}_{6}\right]$ as black lustrous crystal needles. The compound shows a substantial phase field width in the silver content depending on reaction temperature and reaction time and crystals with $\mathrm{x}=0,0.38$ and 0.82 were isolated. The crystal structure determinations (monoclinic, $C 2 / m$ ) show the structure to be isotypic to those of $\mathrm{Tl}\left[\mathrm{W}_{2} \mathrm{O}_{2} \mathrm{Cl}_{6}\right]$ and $\mathrm{K}_{0.84}\left[\mathrm{~W}_{2} \mathrm{O}_{2} \mathrm{Cl}_{6}\right]$ with the presence of $1-\mathrm{D}$ polymeric $\left[\mathrm{W}_{2} \mathrm{O}_{2} \mathrm{Cl}_{6}\right]_{\mathrm{n}}$ strands and $\mathrm{Ag}^{+}$ions with a variety in the occupation of the respective crystallographic site. $\mathrm{Ag}_{1-\mathrm{x}}\left[\mathrm{W}_{2} \mathrm{O}_{2} \mathrm{Cl}_{6}\right]$ represents a mixed valence compound with a variable ratio of $\mathrm{W}(\mathrm{IV})$ and $\mathrm{W}(\mathrm{V})$ in the $\mathrm{W}_{2}$ dumbbells with a short $\mathrm{W}-\mathrm{W}$ separation of $2.85 \AA$ A. In Fourier maps the electron density of the Ag ion appears smeared over a large area. By structure determinations of stochiometric $\mathrm{Ag}_{1.0}\left[\mathrm{~W}_{2} \mathrm{O}_{2} \mathrm{Cl}_{6}\right]$ at temperatures of 123, 193, and 293 $\mathrm{K}$ a double minimum potential was found with the silver ion dynamically disordered over two flat basins with a thermal activation barrier of $13 \mathrm{meV}$. No long range ion mobility is present since the $\mathrm{Ag}^{+}$ions are trapped within a coordinating cage consisting of ten $\mathrm{Cl}$ atoms of the surrounding $\left[\mathrm{W}_{2} \mathrm{O}_{2} \mathrm{Cl}_{6}\right]$ strands forming a distorted bicapped cube. By MAS-NMR measurements on the ${ }^{109} \mathrm{Ag}$ nuclei at different temperature the spin lattice relaxation times were determined giving a thermally activated barrier of $15 \mathrm{meV}$. The electronic conductivity of pressed powder samples of $\mathrm{Ag}\left[\mathrm{W}_{2} \mathrm{O}_{2} \mathrm{Cl}_{6}\right]$ by a four-probe measurement applying direct current is $1 \Omega^{-1} \mathrm{~cm}^{-1}$ at room temperature and $10^{-3} \Omega^{-1} \mathrm{~cm}^{-1}$ at $25 \mathrm{~K}$. For the conduction mechanism at low temperatures a variable range hopping mechanism is suggested while at higher temperatures a standard semi-conductivity with a band gap of $60 \mathrm{meV}$ is present.
\end{abstract}

\footnotetext{
Keywords: Halooxotungstates; Mixed valence compounds; Nonstoichiometry; Ion mobility; ${ }^{109} \mathrm{Ag}$ solid state NMR; Small Gap Semiconductivity
} 


\section{Introduction}

In preceding works we reported on the structure of $\mathrm{WOCl}_{3}$ and the structures and properties of the chlorooxotungstates $M_{x}\left[\mathrm{~W}_{2} \mathrm{O}_{2} \mathrm{Cl}_{6}\right]$ with $M=\mathrm{Tl}^{+}, \mathrm{K}^{+}, \mathrm{Pb}^{2+}, \mathrm{Hg}^{2+}$ and the non-stochiometric phases $\mathrm{Ag}_{0.8}\left[\mathrm{~W}_{2} \mathrm{O}_{2} \mathrm{Br}_{6}\right][1], \mathrm{Cu}_{1-x}\left[\mathrm{~W}_{2} \mathrm{O}_{2} \mathrm{Cl}_{6}\right]$ and $\mathrm{Cu}_{1-x}\left[\mathrm{~W}_{4} \mathrm{O}_{4} \mathrm{Cl}_{10}\right]$ [2]. All compounds represent a family of mixed valence compounds with structures build of negatively charged infinite $\mathrm{W}_{2} \mathrm{O}_{2} X_{6}$ double strands consisting of $\mathrm{WO}_{2} X_{4}$ octahedra condensed via two edge-sharing halogen atoms to form double octahedra and corner-sharing oxygen atoms to build 1-D strands. The mono or divalent cations are located between the strands and connect them to layers. The first representatives of this structure type were the bromooxotungstates $\mathrm{Na}\left[\mathrm{W}_{2} \mathrm{O}_{2} \mathrm{Br}_{6}\right]$ [3] and the non-stochiometric $\mathrm{Ag}_{0.74}\left[\mathrm{~W}_{2} \mathrm{O}_{2} \mathrm{Br}_{6}\right]$ [4]. The structures of these compounds can in principle be understood as intercalates with $\mathrm{WO}_{3}(X=\mathrm{Cl}, \mathrm{Br})$ acting as the host for atoms of the corresponding metals or, in the case of $\mathrm{Cu}_{1-x}\left[\mathrm{~W}_{4} \mathrm{O}_{4} \mathrm{Cl}_{10}\right]$, as intermediates between $\mathrm{WO} X_{3}$ and $\mathrm{WO} X_{2}$. The tungsten(IV) dihalideoxides crystallize most probably isotypic to the structure of $\mathrm{MoOCl}_{2}$ which has been investigated by Thiele et al. $[5,6]$ despite the structure of $\mathrm{WOCl}_{2}$ is not known in detail. $\mathrm{WOCl}_{2}$ is a product of thermal decomposition of $\mathrm{WOCl}_{3}$.

Several of the compounds investigated so far show non-stochiometric compositions with a phase field width pertaining the cations $M$, which are observed to underoccupy their positions. The compounds have been found to be weakly paramagnetic with temperature independent Pauli characteristics and show a remarkably high electrical conductivity of about $0.1 \Omega^{-1} \mathrm{~cm}^{-1}$ or higher at room temperature. The temperature dependence of the conductivity corresponds to semiconducting behaviour with a very small thermal activation barrier for the conduction process of about $0.03 \mathrm{eV}$ at room temperature. The physical properties of the compounds can be understood by an interpretation as being one-dimensional metals. The real structure of the crystals, however, with a high number of discontinuances of the one-dimensional building units, limits the conductivity in close analogy to Krogmann's salts [7].

Here we report on $\mathrm{Ag}_{1-x}\left[\mathrm{~W}_{2} \mathrm{O}_{2} \mathrm{Cl}_{6}\right]$ as the silver containing representative of the $\left(M^{+}\right)_{x}\left[\mathrm{~W}_{2} \mathrm{O}_{2} \mathrm{Cl}_{6}\right]$ family of compounds and its remarkable properties.

\section{Experimental}

All educts and reaction products were handled in an argon filled glove box. Ampoules were made of borosilicate glass and flame-dried in vacuo prior to use. $\mathrm{WOCl}_{4}$ was prepared from freshly precipitated $\mathrm{WO}_{3}$, which was obtained from a $\mathrm{NaWO}_{4}$ solution (Merck) by precipitation with concentrated hydrochloric acid. $\mathrm{WO}_{3}$ was refluxed in $\mathrm{SOCl}_{2}$ (Merck) and the orange solid was isolated by 
filtration under argon. Before use, $\mathrm{WOCl}_{4}$ was sublimated twice [8]. $\mathrm{WOCl}_{3}$ was prepared by reduction of $\mathrm{WOCl}_{4}$ with $\mathrm{Al}$ powder in evacuated borosilicate glass tubes at $500 \mathrm{~K}$. $\mathrm{AlCl}_{3}$ formed in the reaction was sublimated to the cold tip of the ampoule before opening in the glove box. $\mathrm{AgCl}$ was freshly prepared by precipitation from $\mathrm{AgNO}_{3}$ and hydrochloric acid. It was handled in the dark and dried over $\mathrm{P}_{4} \mathrm{O}_{10}$.

\section{Synthesis}

$\mathrm{Ag}_{1-\mathrm{x}}\left[\mathrm{W}_{2} \mathrm{O}_{2} \mathrm{Cl}_{6}\right]$ was prepared by two ways, either by the reduction of $\mathrm{WOCl}_{4}$ with metallic silver (Method A) or by reaction of $\mathrm{WOCl}_{3}$ with $\mathrm{AgCl}$ (Method B), respectively.

Method A: For the reduction of $\mathrm{WOCl}_{4}$ with $\mathrm{Ag} 1965 \mathrm{mg} \mathrm{WOCl} 4$ (5.752 mmol) and $463 \mathrm{mg} \mathrm{Ag}$ powder (4.292 mmol) were filled into an ampoule of $15 \mathrm{~cm}$ length an $1.8 \mathrm{~cm}$ diameter, which was sealed, placed in a horizontal tube furnace and heated to a temperature of $690 \mathrm{~K}$ for a period of 7 days. The product was obtained as black needles with metallic luster. The crystals were separated manually for crystal structure analysis and solid state NMR investigations.

Method B: For the reaction of $\mathrm{WOCl}_{3}$ with silver chloride $136 \mathrm{mg} \mathrm{WOCl}_{3}(0.45 \mathrm{mmol})$ and $70 \mathrm{mg}$ $\mathrm{AgCl}\left(0.49 \mathrm{mmol}\right.$, dried in vacuo) and were filled together with a small amount $(32 \mathrm{mg}) \mathrm{WCl}_{6}$ $(0.08 \mathrm{mmol})$ into an ampoule of $13 \mathrm{~cm}$ length and $6 \mathrm{~mm}$ diameter. This ampoule was placed in a horizontal tube furnace and heated starting from $510 \mathrm{~K}$ up to $700 \mathrm{~K}$ during a period of 40 days. Along the ampoule a temperature gradient of $20 \mathrm{~K}$ was present with the starting materials positioned in the hotter zone. At a temperature of $620 \mathrm{~K}$ crystallization of black needles started. The crystals grew on the surface of the sintered starting materials, chemical transport could not be observed. Crystals were separated manually and the residual ampoule content was grinded and sealed once more in an evacuated ampoule for further reaction at $690 \mathrm{~K}$. A second crop of crystals could be separated manually.

\section{Crystal structure determinations}

Crystals from different synthetic runs were mounted in thin-walled glass capillaries, which were sealed. Data were collected using a Enraf-Nonius-Kappa-CCD diffractometer using graphite monochromatized Mo-K $\alpha$ radiation. Low temperature was maintained with a nitrogen gas flow cooling system (Oxford Cryosystems). Temperatures were calibrated with a micro-thermocouple mounted in the position of a crystal. Data sets were recorded at ambient temperature and additionally at 


\section{Nuclear magnetic resonance analysis}

An amount of selected crystals obtained by method A was grinded and filled into a rotor and sealed by a vespel cap. The rotor was placed inside a $4 \mathrm{~mm}$ MAS probe (Chemagnetics) allowing for a maximum spinning rate of $18 \mathrm{kHz}$ in the temperature range from 120 to $520 \mathrm{~K}$. Data were collected with a $400 \mathrm{MHz}$ spectrometer (Varian Infinity+). A $9 \mathrm{~mol} \mathrm{~L}^{-1} \mathrm{AgNO}_{3}$ solution spiked with $0.25 \mathrm{~mol} \mathrm{~L}^{-1} \mathrm{Fe}\left(\mathrm{NO}_{3}\right)_{3}$ for acceleration of the relaxation process was used as reference.

\section{Conductivity Measurements}

A sample of $\mathrm{Ag}\left[\mathrm{W}_{2} \mathrm{O}_{2} \mathrm{Cl}_{6}\right]$, prepared via method $\mathrm{B}$, was grinded and pressed to a pellet of $6 \mathrm{~mm}$ diameter. The bulk sample was checked by X-ray powder diffractometry and EDX analysis for purity. Only marginal reflections of $\mathrm{AgCl}$ were present with a maximal relative intensity of $1 \%$. The silver content was found to be stochiometric by EDX. Conductivity measurements were performed by four-probe technique applying direct current within the temperature range from $10 \mathrm{~K}$ to $300 \mathrm{~K}$, in both directions with cooling and heating. 


\section{Results and Discussion}

\section{Synthesis}

The silver oxochlorotungstate $\mathrm{Ag}\left[\mathrm{W}_{2} \mathrm{O}_{2} \mathrm{Cl}_{6}\right]$ can be obtained by two different methods. In the presence of $\mathrm{AgCl}$ thermal decomposition of $\mathrm{WOCl}_{3}$ occurs according to Eq. (A).

$\mathrm{AgCl}+3 \mathrm{WOCl}_{3} \rightarrow \mathrm{Ag}\left[\mathrm{W}_{2} \mathrm{O}_{2} \mathrm{Cl}_{6}\right]+\mathrm{WOCl}_{4}$

Metallic silver reduces $\mathrm{WOCl}_{4}$ according to Eq. (B) under formation of $\mathrm{AgCl}$.

$3 \mathrm{Ag}+2 \mathrm{WOCl}_{4} \rightarrow \mathrm{Ag}\left[\mathrm{W}_{2} \mathrm{O}_{2} \mathrm{Cl}_{6}\right]+2 \mathrm{AgCl}$

While reaction A gives the product in higher purity, reaction B gives a higher yield according to the higher reactivity of $\mathrm{WOCl}_{4}$. The higher purity in reaction $\mathrm{A}$ is a consequence of the high volatility of $\mathrm{WOCl}_{4}$, which can be sublimated off from the product whereas $\mathrm{AgCl}$ as the side-product of reaction $\mathrm{B}$ is not volatile. Additionally, the thermal decomposition of $\mathrm{WOCl}_{3}$ to $\mathrm{WOCl}_{2}$ and $\mathrm{WOCl}_{4}$ at the applied temperatures is a distracting rival to the desired reaction and thus lessens the yield. It can be suppressed by adding some $\mathrm{WCl}_{6}$ or some excess $\mathrm{WOCl}_{4}$ into the reaction ampoule. The two different methods of synthesis show a distinct influence on the composition of the products. As indicated by EDX analyses and the results of the single crystal analyses, crystals obtained by method A show constantly a silver tungsten ratio of $1: 2$, indicating stochiometric composition according to the formula $\mathrm{Ag}\left[\mathrm{W}_{2} \mathrm{O}_{2} \mathrm{Cl}_{6}\right]$. Crystals obtained by reaction $\mathrm{B}$ showed a variable silver tungsten ratio of $1: 2,0.66: 2,0.62: 2$ and $0.18: 2$, respectively, according to the site occupancy factors obtained by crystal structure determinations on crystals from different runs. The ratio 1:2, however, was only found in crystals obtained after opening the ampoules after the first reaction cycle, grinding the contents, re-sealing and heating for a second time, as described in the Experimental Part. The occurrence of such a large variety in the silver content is remarkable. The consequence for the charge balance of the crystal is the presence of a corresponding variety in the oxidation state of the tungsten atoms, ranging between +5 in $\mathrm{WOCl}_{3}=\mathrm{W}_{2} \mathrm{O}_{2} \mathrm{Cl}_{6}$ and +4.5 in $\left(\mathrm{Ag}^{+}\right)_{1.0}\left[\mathrm{~W}_{2} \mathrm{O}_{2} \mathrm{Cl}_{6}\right]$.

\section{Crystal structure of $\mathrm{Ag}_{1-x}\left[\mathrm{~W}_{2} \mathrm{O}_{2} \mathrm{Cl}_{6}\right]$}

The crystal structures have been determined for several selected crystals and, for a crystal of the composition $\mathrm{Ag}_{1.0}\left[\mathrm{~W}_{2} \mathrm{O}_{2} \mathrm{Cl}_{6}\right]$, at three different temperatures. All of these crystallize in the mono- 
Refinement of anisotropic displacement parameters for $\mathrm{Ag}^{+}$ions on $(0,1 / 2,1 / 2)$ resulted in an extremely elongated displacement ellipsoid and a high residual electron density. Splitting the position of the $\mathrm{Ag}^{+}$ion over two closely neighboured sites $(0.048,1 / 2,0.501)$ did not solve the problem: though the residual electron density decreased clearly, no change in the elongation of the displacement ellipsoids of the $\mathrm{Ag}^{+}$ions could be obtained. An electron density map in the (010) plane shows a broad region of electron density smeared along [100] with two closely neighboured maxima close to the special position $2 d(2 / m)$ at $(0,1 / 2,1 / 2)$. An alternative model for the refinement was set up, implying four closely neighboured (symmetry generated seven) Ag sites using isotropic displacement parameters. The actual electron density distribution was described better by this structure model, even though strong correlations between parameters of the split Ag atoms occurred. To gain further insight into the phenomenon data sets at low temperature were recorded. At $123 \mathrm{~K}$ the site occupation factor of the 'central' Ag site in $(0,1 / 2,1 / 2)$ became less than its error indicating a decreasing electron density in the central point. So this site was set to 'not occupied' on refinements based on the data collected at this temperature and the model contained six Ag sites (Fig. 1). The occupation factors were allowed for free refinement and finally reached a sum corresponding to the formula $\mathrm{Ag}_{1.02(6)}\left[\mathrm{W}_{2} \mathrm{O}_{2} \mathrm{Cl}_{6}\right]$ (Tab. 2). In a third model, the electron density of the Ag ion was refined using an anharmonic displacement model with the Gram-Charlier expansion of the harmonic displacement tensor (program JANA2000 [13]). The Ag site was split into two symmetric equivalent positions close to $(0,1 / 2,1 / 2)$, each of them refined with a displacement tensor of $3^{\text {rd }}$ order. The residual electron density decreased to an acceptable level but some correlations between parameters persisted. Nonetheless it seems to be a method inherent phenomenon that parameters of the displacement tensor are correlated [14]. Fig. 2 displays electron density charts of the Ag ion and a section along the maxima of the electron density at $295 \mathrm{~K}, 193 \mathrm{~K}$, and $123 \mathrm{~K}$, and the shape of the anhar- 
monic displacement parameters. At ambient temperature, the electron density of the $\mathrm{Ag}$ ion is blurred over a distance of nearly $4 \AA$ with two flat maxima, representing preferred positions for the Ag ion. On decreasing temperature the two maxima of electron density persist but these maxima become sharper and the distance between the maxima increases from 1.24(2) $\AA$ at $295 \mathrm{~K}$ to $1.473(8) \AA$ at $123 \mathrm{~K}$. The Ag ions are actually located in a double-minimum potential with a saddle point of low energy. According to Boltzmann's distribution theorem $\frac{N_{E+\Delta E}}{N_{E}}=e^{\frac{-\Delta E}{k T}}$, the electron density diagram can be transferred into a potential diagram assuming that the electron density represents the population of the respective position and the observed maximal electron density as the population of the lowest energy state $N_{E}$. The result is shown at the bottom of Fig. 2 from which the activation energy for the thermally activated hopping of the $\mathrm{Ag}^{+}$ion between the two most preferential positions at $123 \mathrm{~K}$ is estimated to $10 \mathrm{meV}$ or $1 \mathrm{~kJ} \mathrm{~mol}^{-1}$. This fits with the thermal energy $k T$, which corresponds to $11 \mathrm{meV}$ at $123 \mathrm{~K}$.

In the crystal structure, the $\mathrm{Ag}^{+}$ions exhibit a distorted bicapped cuboidal coordination environment. The coordination polyhedron consists of eight $\mathrm{Cl}(2)$ and $\mathrm{Cl}(3)$ atoms with cuboidal shape, which is capped by two additional $\mathrm{Cl}(3)$ atoms (Fig. 1). This is caused by the lattice centering, which shifts the planar $\mathrm{W}_{2} \mathrm{Cl}_{6}$ groups alternately by half of the lattice constant in the $b$ direction and brings two $\mathrm{Cl}(3)$ atoms of two neighbouring $\left[\mathrm{W}_{2} \mathrm{O}_{2} \mathrm{Cl}_{6}\right]$ strand in positions over two opposite faces of the cuboidal void in the crystallographic $a$ direction. Thus the migration paths of the $\mathrm{Ag}^{+}$ions are blocked and no long range ion mobility is possible since the structure of the anionic lattice does not offer non-intermittent migration paths for ionic conduction and only a local mobility is observed. The $\mathrm{Ag}-\mathrm{Cl}$ distances amount 2.582(6) $\left(\mathrm{Ag}(4)-\mathrm{Cl}(2)^{\mathrm{VII}}\right), 2.653(6)(\mathrm{Ag}(4)-\mathrm{Cl}(3)), 2.976(6) \AA$ $\left(\mathrm{Ag}(4)-\mathrm{Cl}(3)^{\mathrm{VI}}\right)$ for the different $\mathrm{Ag}$ sites and are comparable for example with the $\mathrm{Ag}-\mathrm{Cl}$ distances in $\mathrm{Ag}_{3} \mathrm{YCl}_{6}$ (2.570 to $2.733 \AA$ ) [15]. $\mathrm{Ag}_{3} \mathrm{YCl}_{6}$ also contains disordered $\mathrm{Ag}$ ions with an elongated electron density inside a pair of face sharing octahedra. A comparable situation is observed for one of the $\mathrm{Cu}$ ions in the structure of tetrahedrite, $\mathrm{Cu}_{12} \mathrm{Sb}_{4} \mathrm{~S}_{13}$ [16]. The $\mathrm{Cu}$ ion is located in a trigonal bipyramidal coordination environment with three $\mathrm{S}$ atoms in the equatorial plane and two antimony atoms at the apexes. A dynamic disorder perpendicular to the triangular plane was observed by temperature dependent structure determinations.

From the structure analyses of the silver deficient crystals the tendency is present that on decreasing silver content an increasing $\mathrm{W}-\mathrm{W}$ distance follows. With fully occupied silver sites in 


\section{Nuclear magnetic resonance analysis}

To gain further insight into the ionic motion process a nuclear resonance analysis was performed. MAS-NMR measurements on ${ }^{109} \mathrm{Ag}$ nuclei were performed to obtain the isotropic chemical shift of the silver ions. The MAS-NMR spectrum shows one signal at $232.0 \mathrm{ppm}$ referenced to $\mathrm{AgNO}_{3}$ (Fig. 3) This result is in accordance with the results of the X-ray single crystal structure analysis, which showed the equivalence of the two minima of the double minimum potential. Further measurements aimed on the longitudinal relaxation time $T_{1}$. A sequence of pulses was used to make the magnetization fade out. After a pulse delay $(p d)$ a rectangular pulse was set to excite ${ }^{109} \mathrm{Ag}$ nuclei. The free induction decay $F I D$ was plotted against $p d$. This procedure was performed at different temperatures of 265, 300, 330 and $355 \mathrm{~K}$. By using the Bloch equation [17] the spin lattice relaxation time was calculated. The obtained relaxation times were plotted semi-logarithmic against the reciprocal values of the corresponding temperatures (Fig. 3). By fitting a linear slope to the data points, the Arrhenius equation can be applied and the activation energy of the $\mathrm{Ag}^{+}$ion motion thus be calculated. The Arrhenius plot showed a linear alignment following $\log T_{1}=0.6908+175.96 \mathrm{~K} \cdot T^{-1}$. According to $\log T_{1}=\log k_{0}-\frac{E_{A}}{R} K T^{-1}$ the activation energy is calculated to $15.1 \mathrm{meV}$.

\section{Electrical Conductivity}

Like the others so far examined members of the $M_{x}\left[\mathrm{~W}_{2} \mathrm{O}_{2} \mathrm{Cl}_{6}\right]$ series, $\mathrm{Ag}\left[\mathrm{W}_{2} \mathrm{O}_{2} \mathrm{Cl}_{6}\right]$ is a good electrical conductor. At room temperature, a specific conductivity of about $1 \Omega^{-1} \mathrm{~cm}^{-1}$ was found on a pressed powder sample. The temperature characteristics is semi-conducting, since the conductivity decreases with decreasing temperature and reaches about $10^{-3} \Omega^{-1} \mathrm{~cm}^{-1}$ at $25 \mathrm{~K}$ (Fig. 4).

From the Arrhenius equation for the activation energy of current transport in semiconductors one gets $\sigma(T)=\sigma_{0} \cdot e^{-\frac{\Delta E}{2 k T}}$. Accordingly, $-\ln \sigma=f\left(T^{-1}\right)$ is expected as a linear function. As Fig. 4 shows, 
a linear function is actually present in the temperature range between $70 \mathrm{~K}$ and $300 \mathrm{~K}$. From the slope the energy of the thermal activation is calculated to $0.0298(1) \mathrm{eV}$. This corresponds to a band gap of $\Delta \mathrm{E}=0.0596(2) \mathrm{eV}$. In the range below $70 \mathrm{~K}$ the activation energy decreases with decreasing temperature and a linear function is no longer present. This behaviour may be interpreted with a variable range hopping mechanism $(V R H)$, describing the low temperature behaviour of the conductivity in disordered solids. The temperature dependence of the conductivity follows the expression $\sigma(T)=\sigma_{0} \cdot e^{-\left(\frac{T_{0}}{T}\right)^{\alpha}}$ [18]. Initially developed for amorphous solids, the model is nowadays used also for crystalline semiconductors [19]. The exponent $\alpha$ is critical towards the dimensionality of the process and is assumed to be 0.5 for $1 \mathrm{D}$ systems [20]. As can be seen from Fig. 4, a satisfying fit to the conductivity data can be obtained with the exponent $\alpha=0.53(2)$.

\section{Conclusion}

$\mathrm{Ag}_{1-\mathrm{x}}\left[\mathrm{W}_{2} \mathrm{O}_{2} \mathrm{Cl}_{6}\right]$ represents a further member of the $A_{1-\mathrm{x}}\left[\mathrm{W}_{2} \mathrm{O}_{2} X_{6}\right]$ family of compounds. A large phase field width has been achieved for the Ag containing compound, ranging from full occupation of the $\mathrm{Ag}^{+}$site down to an occupation of merely $18 \%$. The $\mathrm{Ag}^{+}$ions are mobile within their cuboidal coordination sphere in a double minimum potential and are dynamically disordered with an activation energy in the order of $k \mathrm{~T}$, shown by temperature dependent structure analyses and spin lattice relaxation times based on ${ }^{109} \mathrm{Ag}$ solid state NMR spectra. The crystal structure, however, does not allow for a long range mobility of the $\mathrm{Ag}^{+}$ions, since there are no continuous migration paths for the $\mathrm{Ag}^{+}$ions. Like all other members of the $A_{1-\mathrm{x}}\left[\mathrm{W}_{2} \mathrm{O}_{2} X_{6}\right]$ family of compounds, $\mathrm{Ag}\left[\mathrm{W}_{2} \mathrm{O}_{2} \mathrm{Cl}_{6}\right]$ exhibits a remarkable high electrical conductivity with semiconducting characteristics and a small band gap of approximately $60 \mathrm{meV}$.

\section{Acknowledgement}

We are much obliged to J. Daniels for measuring the X-ray diffraction data sets and to Prof. M. Jansen, Max-Planck-Institute for Solid State Research in Stuttgart, Germany, for giving the opportunity for the conductivity measurements. 
Table 1 Crystallographic data and details of the crystal structure determination of $\mathrm{Ag}_{1.0}\left[\mathrm{~W}_{2} \mathrm{O}_{2} \mathrm{Cl}_{6}\right]$. The refinement is based on the model for the Ag electron density by 4 ( $295 \mathrm{~K}$ und $193 \mathrm{~K}$ ) or 3 (123 $\mathrm{K})$ closely neighboured sites. Ag atoms are refined with isotropic displacement parameters. The standard deviations in brackets refer to the last quoted digit.

\begin{tabular}{|c|c|c|c|}
\hline Formula & \multicolumn{3}{|c|}{$\mathrm{Ag}\left[\mathrm{W}_{2} \mathrm{O}_{2} \mathrm{Cl}_{6}\right]$} \\
\hline Crystal system, space group & \multicolumn{3}{|c|}{ monoclinic, $C 2 / m$} \\
\hline Temperature of measurement / K & $295(2)$ & $193(3)$ & $123(3)$ \\
\hline Lattice parameters / $\AA$ & $\begin{array}{l}a=12.9211(3) \\
b=3.7631(1) \\
c=9.8663(3) \\
\beta=109.064(1)\end{array}$ & $\begin{array}{l}a=12.8737(3) \\
b=3.7629(1) \\
c=9.8525(2) \\
\beta=109.161(1)\end{array}$ & $\begin{array}{l}a=12.8499(6) \\
b=3.7626(2) \\
c=9.8477(5) \\
\beta=109.227(2)\end{array}$ \\
\hline Cell volume / $\AA^{3}$ & $453.42(2)$ & $450.84(2)$ & $449.57(4)$ \\
\hline Number of formula units & \multicolumn{3}{|c|}{2} \\
\hline Calculated density $\left./ \mathrm{g} \mathrm{cm}^{-3}\right]$ & 5.276 & 5.306 & 5.321 \\
\hline Crystal size $/ \mathrm{mm}^{3}$ & \multicolumn{3}{|c|}{$0.019 \times 0.112 \times 0.018$} \\
\hline Radiation & \multicolumn{3}{|c|}{$\operatorname{Mo}-K_{\alpha}^{-}(\lambda=0.71073 \AA)$} \\
\hline Data collection range $/{ }^{\circ}$ & $6.7 \leq 2 \theta \leq 55.0$ & $6.7 \leq 2 \theta \leq 55.0$ & $9.1 \leq 2 \theta \leq 54.9$ \\
\hline $\min . / \max . h k l$ & $\begin{array}{l}-16 \leq h \leq 16 \\
-4 \leq k \leq 4 \\
-12 \leq l \leq 12\end{array}$ & $\begin{array}{l}-16 \leq h \leq 16 \\
-4 \leq k \leq 4 \\
-12 \leq l \leq 12\end{array}$ & $\begin{array}{l}-16 \leq h \leq 16 \\
-4 \leq k \leq 4 \\
-12 \leq l \leq 12\end{array}$ \\
\hline Number of measured reflections & 5736 & 5303 & 2395 \\
\hline Number of independent reflections & 598 & 594 & 584 \\
\hline Data quality $R_{\text {int }} / R_{\text {sigma }}$ & $0.051 / 0.019$ & $0.058 / 0.025$ & $0.088 / 0.056$ \\
\hline Number of refined parameters & 46 & 46 & 44 \\
\hline Relation reflections / parameters & 13.0 & 12.9 & 13.3 \\
\hline Absorption coefficient $\mu / \mathrm{cm}^{-1}$ & 291.5 & 293.2 & 294.0 \\
\hline Min. / max. transmission & $0.2599 / 0.7014$ & $0.2561 / 0.7672$ & $0.2857 / 0.7640$ \\
\hline $\begin{array}{l}\text { Quality of refinement } \\
\qquad \begin{array}{l}\mathrm{R}(|F|) \\
\mathrm{R}(|F|)\left(\mathrm{n}\left(F_{\mathrm{o}}\right)>4 \sigma\left(F_{\mathrm{o}}\right)\right) \\
w \mathrm{R}\left(F^{2}\right) \\
\text { GooF }\end{array}\end{array}$ & $\begin{array}{l}0.015 \\
0.013(566) \\
0.029 \\
1.04\end{array}$ & $\begin{array}{l}0.015 \\
0.014(577) \\
0.032 \\
1.16\end{array}$ & $\begin{array}{l}0.025 \\
0.024(562) \\
0.054 \\
1.07\end{array}$ \\
\hline $\max . / m i n$. residual electron density $\left[\mathrm{e} \AA^{-3}\right]$ & $+0.92 /-0.87$ & $+0.89 /-0.84$ & $+1.30 /-1.49$ \\
\hline
\end{tabular}


Table 2 Positional parameters and equivalent isotropic displacement factors $U$ of the atoms in the structure of $\mathrm{Ag}\left[\mathrm{W}_{2} \mathrm{O}_{2} \mathrm{Cl}_{6}\right]$ at $123 \mathrm{~K}$. Values in brackets are standard deviations referring to the last quoted digit. All atoms are located on Wyckoff site $4 i$ with site symmetry $m$. SOF is the respective site occupation factor for the split positions of the Ag atom. The sum of the occupation factors amounts $\sum S O F_{2 \mathrm{Ag}(2)+2 \mathrm{Ag}(3)+2 \mathrm{Ag}(4)}=1.02(6)$

\begin{tabular}{lccccc}
\hline Atom & SOF & \multicolumn{1}{c}{$x$} & $y$ & $z$ & $U_{\text {eq }} / \AA^{2}$ \\
\hline $\mathrm{W}$ & & $0.01132(3)$ & 0 & $0.14890(3)$ & $0.00698(18)$ \\
$\mathrm{O}$ & & $0.0096(5)$ & $1 / 2$ & $0.1466(5)$ & $0.0085(13)$ \\
$\mathrm{Cl}(1)$ & & $0.15815(18)$ & 0 & $0.0503(2)$ & $0.0101(4)$ \\
$\mathrm{Cl}(2)$ & & $0.15555(18)$ & 0 & $0.3716(2)$ & $0.0141(5)$ \\
$\mathrm{Cl}(3)$ & & $-0.10774(19)$ & 0 & $0.2928(2)$ & $0.0151(4)$ \\
$\mathrm{Ag}(2)$ & $0.13(2)$ & $0.023(3)$ & $1 / 2$ & $0.4962(11)$ & $0.016(2)$ \\
$\mathrm{Ag}(3)$ & $0.265(17)$ & $0.058(2)$ & $1 / 2$ & $0.5025(8)$ & $0.0131(15)$ \\
$\operatorname{Ag}(4)$ & $0.114(13)$ & $0.099(2)$ & $1 / 2$ & $0.5240(15)$ & $0.016(3)$ \\
\hline
\end{tabular}




\section{References}

[1] J. Beck, Ch. Kusterer, R.-D. Hoffmann, R. Pöttgen, J. Solid State Chem. 2006, 179, 2298-2309.

[2] J. Beck, Ch. Kusterer, Z. Anorg. Allg. Chem. 2008, 634, 587-592.

[3] Y.-Q. Zheng, K. Peters, H.G. v. Schnering, Z. Anorg. Allg. Chem. 1998, 624, 1415-1418.

[4] S. Imhaïne, C. Perrin, M. Sergent, Mat. Res. Bull. 33 (1998) 927-933.

[5] P. Zönnchen, G. Thiele, C.Hess, C. Schlenker, H. Bengel, H.-J. Cantow, S.N. Magonov, D.K.Seo, M.-H. Whangbo, New J. Chem. 1996, 20, 295-300.

[6] H. Hillebrecht, P. J. Schmidt, H. W. Rotter, G. Thiele, P. Zönnchen, H. Bengel, H.-J. Cantow, S. N. Magonov, M.-H. Whangbo, J. Alloys Comp. 1997, 246, 70-79.

[7] P. Würfel, H. D. Hausen, K. Krogmann, P. Stampel, Phys. Stat. Sol.(A) 1972, 10, 537-541.

[8] H.-J. Lunk, W. Petke, Z. Chem. 1974, 14, 365.

[9] R. Colton, I. B. Tomkins, Austral. J. Chem. 1965, 18, 447 - 452.

[10] W. Herrendorf, H. Bärnighausen, HABITUS, Program for the Numerical Absorption Correction, Universities of Karlsruhe and Gießen, Germany, 1993,1997.

[11] G. M. Sheldrick, SHELX97 [includes SHELXS97, SHELXL97, CIFTAB] - Programs for Crystal Structure Analysis (Release 97-2). University of Göttingen, Germany, 1998.

[12] L. J. Farrugia, J. Appl. Cryst. 1999, 32, 837-838.

[13] V. Petricek, M. Dusek, L. Palatinus, Jana2000 - The crystallographic computing system, Institute of Physics, Praha, Czech Republic, 2000. 
[14] B. Bagautdinov, J. Luedecke, M. Schneider, S. van Smaalen, Acta Crystallogr. B 1998, 54, 626-634.

[15] K. Lerch, W. Laqua, G. Meyer, Z. Anorg. Allg. Chem. 1990, 582, 143-150.

[16] A. Pfitzner, M. Evain, V. Petricek, Acta Crystallogr. 1997, B53, 337-345.

[17] H. W. Spieß, R. Grosescu, U. Haeberlen, Chem. Phys. 1974, 6, 226-234.

[18] N. F. Mott, E. A. Davis, Electronic Processes in Non-Crystalline Solids, Oxford University Press, London, 1971.

[19] Ch. Büscher, U. Stöhr, W. Freyland, Phys. Chem. Chem. Phys. 2000, 2, 2261-2264; R. Pocha, D. Johrendt, B. Ni, M. M. Abd-Elmeguid, J. Amer. Chem. Soc. 2005, 127, 8732-8740; E. Arushanov, S. Siebentritt, T. Schedel-Niedrig, M. Ch. Lux-Steiner, J. Appl. Phys. 2006, 100, 063715.

[20] P. A. Lee, Phys. Rev. Lett. 1984, 53, 2042-2045; M. M. Fogler, S. Teber, B. I. Shkloskii, Phys. Rev. 2004, 69B, 035413/1-18. 


\section{Legends for Figures}

Fig. 1 Section of the chain of edge sharing pairs of $\left[\mathrm{WO}_{2 / 2} \mathrm{Cl}_{2} \mathrm{Cl}_{2 / 2}\right]$ octahedra in the structure of $\mathrm{Ag}_{1.0}\left[\mathrm{~W}_{2} \mathrm{O}_{2} \mathrm{Cl}_{6}\right]$ at $123 \mathrm{~K}$ (top), the unit cell of $\mathrm{Ag}_{1.0}\left[\mathrm{~W}_{2} \mathrm{O}_{2} \mathrm{Cl}_{6}\right]$ in a view along the crystallographic $b$ axis (middle, the Ag ions are represented by their harmonic displacement components $U_{\mathrm{ij}}$ ), and the coordination of the dynamically disordered $\mathrm{Ag}$ ion by surrounding $\mathrm{Cl}$ atoms (bottom, the $\mathrm{Ag}$ ions are represented by their isotropic displacement components $U$ ). The displacement spheres and ellipsoids comply with a probability of localization of $90 \%$. Bond lengths $/ \AA$ and angles $/{ }^{\circ}$ at 123 $\mathrm{K}: \mathrm{W}-\mathrm{W}^{\mathrm{I}}$ 2.8501(4), W-O, W-O ${ }^{\mathrm{II}} 1.8815(1), \mathrm{W}-\mathrm{Cl}(1)$ 2.390(2), W-Cl(1) ${ }^{\mathrm{I}} 2.403(2), \mathrm{W}-\mathrm{Cl}(2)$ 2.404(2), W-Cl(3) 2.360(2), O-W-O ${ }^{\mathrm{II}}$ 178.5(4), $\mathrm{Cl}(1)-\mathrm{W}-\mathrm{Cl}(1)^{\mathrm{I}}$ 107.03(6), $\mathrm{Cl}(2)-\mathrm{W}-\mathrm{Cl}(3)$ 84.83(7), $\mathrm{W}-\mathrm{Cl}(1)-\mathrm{W}^{\mathrm{I}}$ 72.97(6). Symmetry generated atoms are marked by superscript indices : $\mathrm{I}=$ $-\mathrm{x}, \mathrm{y},-\mathrm{z} ; \mathrm{II}=\mathrm{x},-1+\mathrm{y}, \mathrm{z} ; \mathrm{III}=-\mathrm{x}, \mathrm{y}, 1-\mathrm{z} ; \mathrm{IV}=\mathrm{x}, \mathrm{y}, 1-\mathrm{z} ; \mathrm{V}=\mathrm{x}, 1+\mathrm{y}, \mathrm{z} ; \mathrm{VI}=1 / 2-\mathrm{x}, 1 / 2+\mathrm{y}, 1-\mathrm{z} ; \mathrm{VII}=$ $-\mathrm{x}, 1+\mathrm{y}, 1-\mathrm{z}$.

Fig. 2 Representation of the electron density of the $\mathrm{Ag}$ ion in the structure of $\mathrm{Ag}_{1.0}\left[\mathrm{~W}_{2} \mathrm{O}_{2} \mathrm{Cl}_{6}\right]$ (left, based on Fourier coefficients $F_{\mathrm{O}}$, axis labellings refer to crystal coordinates, contour lines are graded by $2 \mathrm{e} / \AA^{3}$ ), sections of the electron density function through the maxima parallel to the crystallographic $c$ axis (middle) and representations of the anharmonic displacements of the Ag atoms, drawn to include a probability density of $70 \%$ (right). On bottom the respective double-minimum potential function for the $\mathrm{Ag}$ ion at $140 \mathrm{~K}$ is shown.

Fig. $3{ }^{109} \mathrm{Ag}$ MAS NMR spectrum of $\mathrm{Ag}_{1.0}\left[\mathrm{~W}_{2} \mathrm{O}_{2} \mathrm{Cl}_{6}\right]$, recorded with a rotation frequency of $10 \mathrm{kHz}$ (top) and the function of the spin lattice relaxation time at different temperatures versus the reciprocal temperature including the corresponding linear regression function (bottom).

Fig. 4 Electrical conductivity of a compressed sample of $\mathrm{Ag}_{1.0}\left[\mathrm{~W}_{2} \mathrm{O}_{2} \mathrm{Cl}_{6}\right]$ as a function of temperature. The conductivity is shown on a logarithmic scale (top) and the respective Arrhenius function $-\ln \sigma=f\left(T^{-1}\right)$ (bottom). Two different functions have been fitted to the data, a linear fit for the high temperature region (a) and a fit according the $V R H$ model (b). 

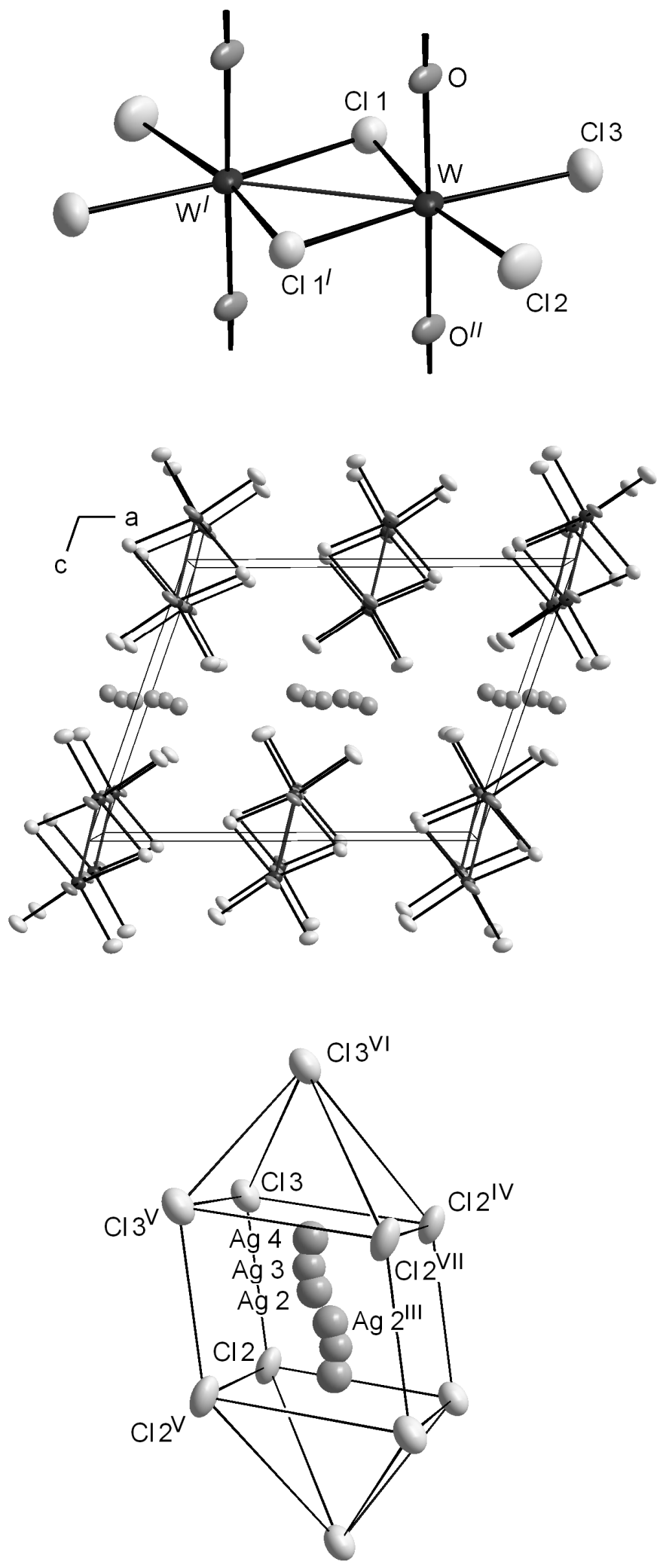

Fig. 1 

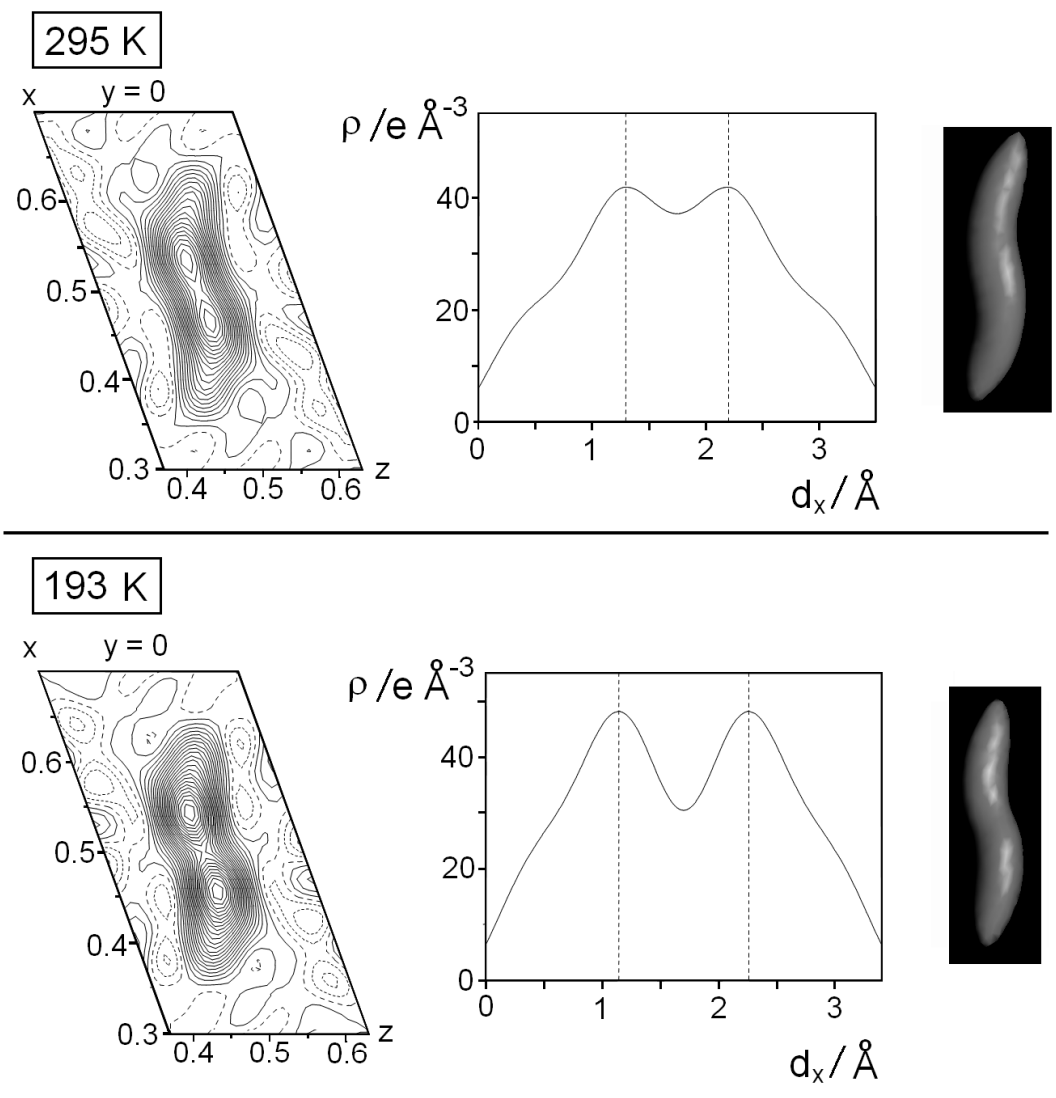

$$
123 \mathrm{~K}
$$
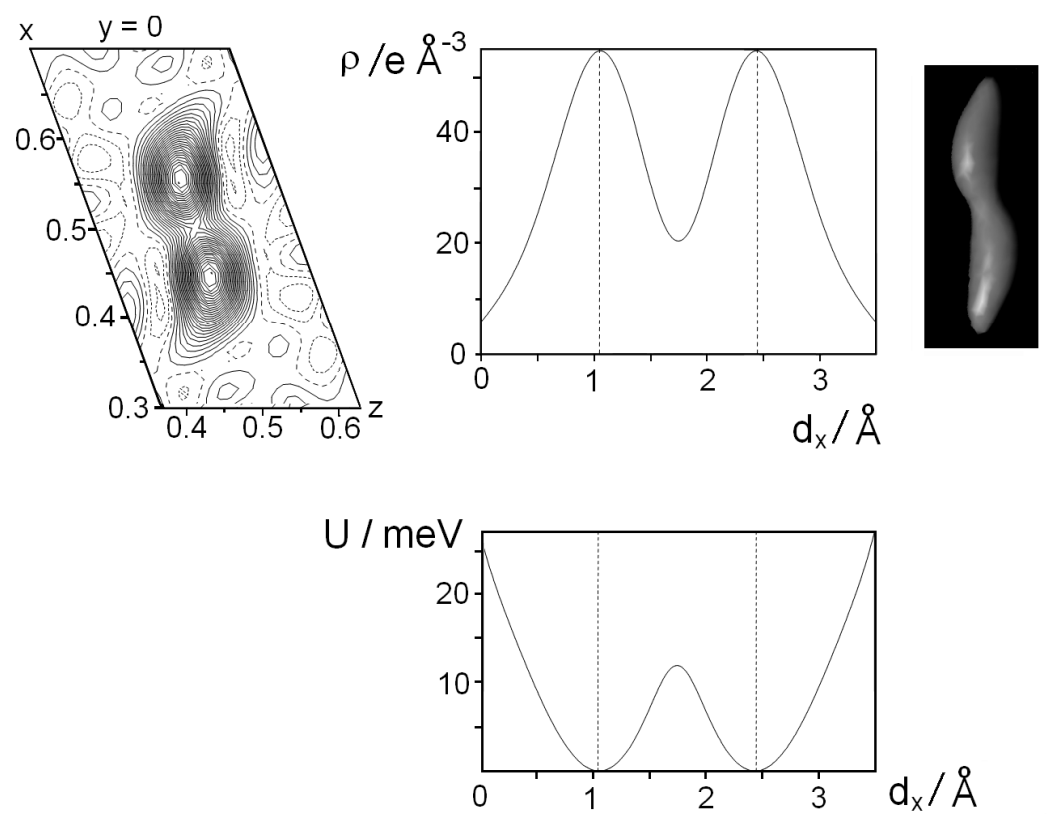

Fig. 2 

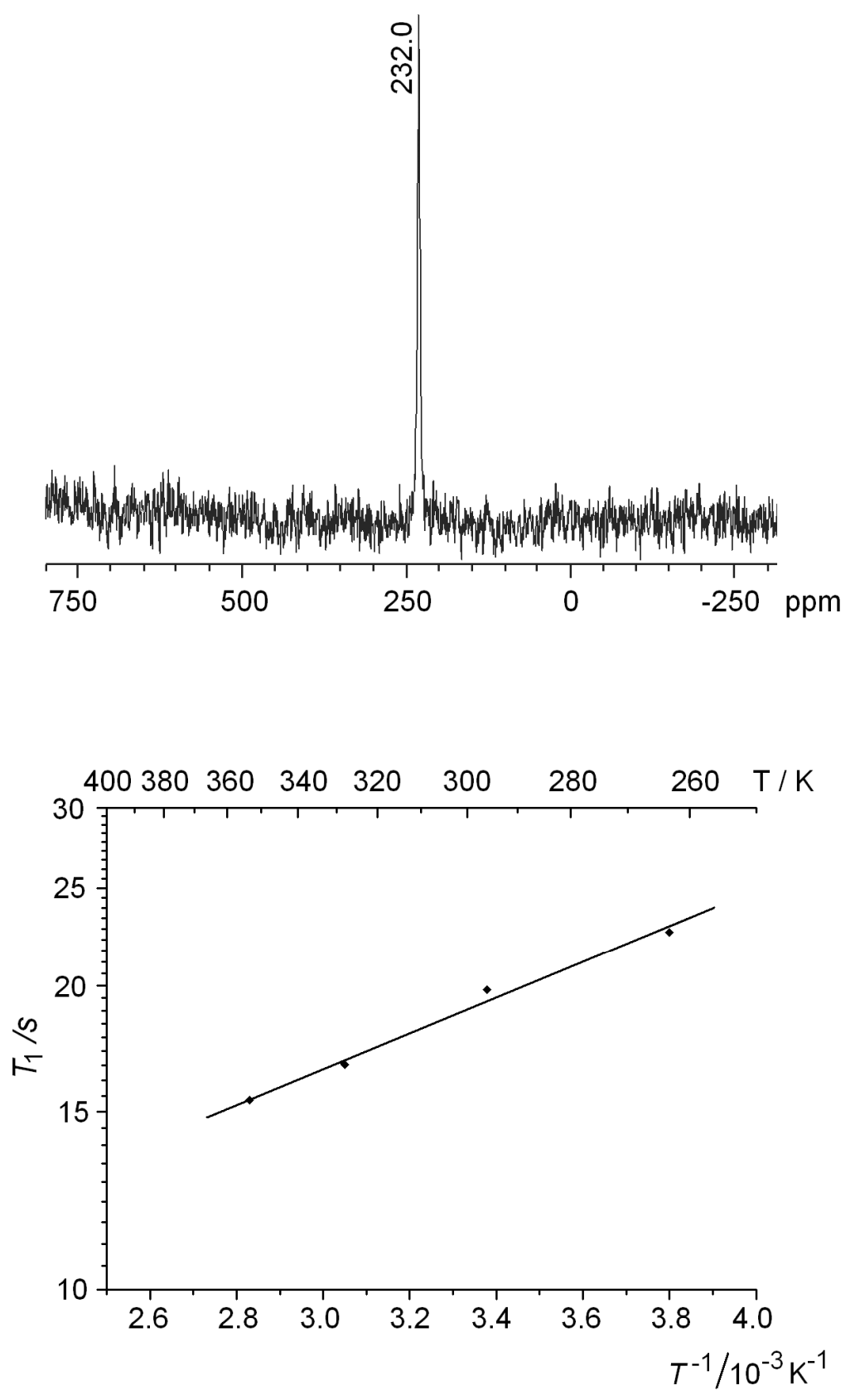

Fig. 3 

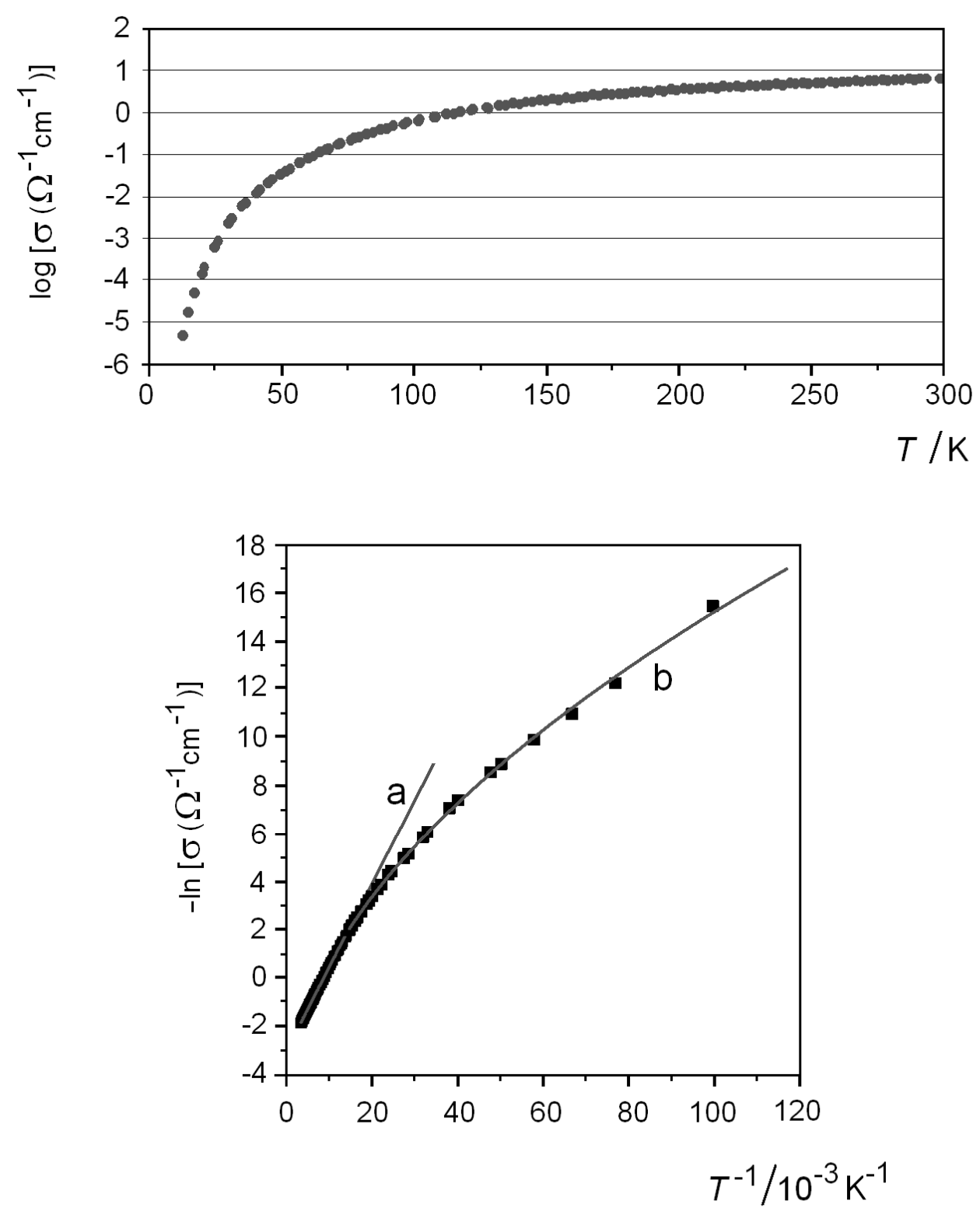

Fig. 4 